Article

\title{
Integrating Repair into Product Design Education: Insights on Repair, Design and Sustainability
}

\author{
Nazlı Terzioğlu *(i) and Renee Wever*(i) \\ Department of Management and Engineering, Linköping University, SE-581 83 Linköping, Sweden \\ * Correspondence: nazli.terzioglu@brunel.ac.uk (N.T.); renee.wever@liu.se (R.W.)
}

Citation: Terzioğlu, N.; Wever, R. Integrating Repair into Product Design Education: Insights on Repair, Design and Sustainability. Sustainability 2021, 13, 10067. https://doi.org/10.3390/ su131810067

Academic Editors: Vicky Lofthouse and Ksenija Kuzmina

Received: 5 August 2021

Accepted: 3 September 2021

Published: 8 September 2021

Publisher's Note: MDPI stays neutral with regard to jurisdictional claims in published maps and institutional affiliations.

Copyright: (c) 2021 by the authors. Licensee MDPI, Basel, Switzerland. This article is an open access article distributed under the terms and conditions of the Creative Commons Attribution (CC BY) license (https:// creativecommons.org/licenses/by/ $4.0 /)$.

\begin{abstract}
With the pressure of growing environmental problems, the world is changing, and so is the paradigm of design. Accordingly, the calls for change in design education are increasing throughout the literature day by day. As the designers of the future, students must be prepared for alternative scenarios. This paper provides insights into students' learning outcomes and competencies related to repair and sustainability in the context of an assignment that integrates repair into design education. This assignment has been part of the master's degree design course at Linköping University for the last 3 years. During these 3 years, 52 repair projects, including a diverse range of products, were developed. Aiming to find out the insights of this process, focus group sessions were conducted. As a result of these focus group sessions, 12 insights were developed, such as the concepts of brokenness, designed repair, and repair-worthy objects. Findings show that practices of repair constitute complex sites of learning, technical skill and knowledge which could enable novice designers to become competent in circular design. This paper is of value for design educators and researchers, especially those concerned with the repair and circular economy, as it can facilitate future attempts to further integrate circular strategies into design education.
\end{abstract}

Keywords: repair; product design; design education; sustainable design; circular economy

\section{Introduction}

The current paradigm of product design education often serves the linear system and perpetuates a throw-away mentality. As the linear economy has brought us to a global ecological crisis, alternative systems such as a circular economy are needed to overcome these problems [1-4]. Designers play a significant role in mitigating today's environmental problems [5], and in the transition towards a circular economy [6]. Students, as the future designers, must be prepared for alternative scenarios and be equipped with the relevant knowledge to be able to deal with environmental issues. This need to solve this issue can be seen from the increasing calls for change in design education throughout the literature [5-11]. Many educational resources, courses, and projects exist that aim to incorporate sustainability and a circular economy into product design education [12-15]. However, there is an insufficient number of these courses, and few of them focus on repair and the competencies related to it. In fact, most product design programs solely offer industrial design, thus catering to mass production in a capitalistic economic setting. Inherent in such programs is the belief that there is a need for new products. If there are needs in the world, then newly designed, better-quality products will help to fulfil those needs. Not being asked to design new products may feel quite unsettling to a product designer, yet a system that is not based on new products still requires a wide range of designer skills.

As a field, design has a largely unquestioned underlying paradigm; that any problem requires a new design to be put into the world. Papanek [16] has already argued that many designers focus on designing the wrong products, developing things that are often unnecessary, and sometimes even dangerously unsafe, all in an effort to sell more products. 
He argues that designers bear the responsibility for which problems they choose to work on solving. Fundamentally, however, that leaves the notion that new designs are needed, untouched. This belief in 'the new' runs very deep. Edgerton [17] already argued that our narratives about 'the new' are too focused on just the stories of inventors, ignoring how long the alternative systems could last. Designers should reflect much more on what is already in the world and question whether a new design will truly create an improvement. We explore how focusing on repair might help challenge this underlying notion.

To be able to design repairable products, designers need a particular set of knowledge and skills. Existing research in this area is sparse and it primarily covers design for sustainability and the circular economy competencies $[18,19]$. For example, Sumter et al. [19] provides a coherent overview of the existing literature about the circular economy competencies for design and identifies seven competencies that designers need to be able to successfully design products and services for a circular economy. Two of these competencies are specifically related to designing repairable products: (1) Design for Recovery, (2) Design for Multiple Use Cycles. Design for recovery refers to the consideration of repair, refurbishment, remanufacturing, and other recovery strategies to regenerate the value of the products between use cycles and at the end of the product's life [19]. Similarly, design for multiple use cycles is about implementing these recovery strategies in the design of the product, considering the effects of long-term use and multiple recoveries on the current design [19]. Similarly, Wiek et al. [20] explain "anticipatory competency" that is also required to design repairable products. The authors describe this competency as the ability to envision the scenarios and the problems that might occur in the future and having the knowledge to answer these problems by using sustainability principles. Designers need to anticipate the future usage scenarios of the products and establish their possible breakdown reasons to invent suitable design solutions for repairability.

This paper provides insights into students' learning outcomes and competencies related to repair and sustainability in the context of an assignment that integrates repair into design education. This assignment, called "Beautiful Repair", has been part of the master's degree design course at Linköping University for the last 3 years. It was prepared for the first part of a master's degree studio course which consists of three assignments and an exhibition. The Beautiful Repair assignment explores how repair can enhance the value, character, and aesthetics of a product. The other two parts study different aspects of repair, such as the social aspect of repair and systems thinking. The course is compulsory for first-year students in the design programme. In the last 3 years, 42 students took this course with diverse backgrounds such as product design, electrical engineering, and business and management. The duration of this assignment was 10 weeks. The requirement of the assignment for each student was to visibly repair one or more products in an aesthetically pleasing way by using different design perspectives, such as artistic, industrial, and critical perspectives. The brief of the assignment is presented in Appendix A. We identified three learning outcomes based on the structure and content of the assignment, considering the existing literature on circular economy competencies. As a result of participating in this assignment, the student would demonstrate a knowledge of design for repair, product longevity and sustainability, with an emphasis on the creative process by:

1. Acknowledging design for repair as an effective recovery strategy to increase product use-life;

2. Understanding the requirements of designing repairable products, such as considering the effects of long-term use and multiple recoveries;

3. Understanding the terminology associated with product repair such as designed repair, product breakdown, aesthetics of repair, different repair perspectives and methods, etc.

Students were instructed in the fundamental aspects of the circular economy, system thinking and environmental problems. They had the freedom to choose the product they wanted to repair and the repair method. Throughout the process students were guided, relevant examples were shown, and their progress was discussed. Finally, the students 
developed 52 visible repair projects. They repaired a diverse range of physically damaged products including a bicycle, leggings, and a motorcycle part. A photograph of each project can be seen in Appendix B.

\section{Methods}

The aim of this paper was to explore the insights that students gained related to learning outcomes and competencies about sustainability and repair in a course that integrated repair into product design education. In order to explore and identify students' insights, a focus group method was considered the most appropriate for this research. This research method enabled a deeper understanding of individual insights through "live encounters" with the participants [21] (p. 12). A focus group session was conducted with the students each year for three years that lasted around $90 \mathrm{~min}$. The first and second focus groups were conducted face-to-face while the third one was conducted online because of the COVID-19 restrictions. Two moderators facilitated the sessions and made sure that all these areas were covered during the discussion. In total, 42 students attended the sessions, including 15 in the first year, 4 in the second year, and 23 in the third year. Appendix $C$ presents the list of students and their projects for each year.

During the focus group sessions, the emphasis was not on asking many questions but on the theme and insights that created an interactive discussion rather than a within-group survey [21]. A natural and comfortable atmosphere was achieved so that students were encouraged to express different points of view and did not feel pressurized [22]. Involving all the students created an extensive discussion and probing environment. This particularly enhanced the potential diversity of the insights and perspectives generated. A wealth of insights was provided by the students and each insight was discussed according to its relevance to each repair project.

All focus group sessions were recorded and fully transcribed. Content analysis [23] was used to analyse the collected data. The results of each year were analysed separately soon after the focus groups were conducted. The students' answers with similar meanings and connotations were grouped into clusters. Each cluster was coded under a relevant title. The coding process resulted in 63 codes for the first year, 35 codes for the second year and 67 codes for the third year. Then, we defined how each code answered the research aim, which was to explore and define the insights related to sustainability and repair. With the help of this definition process, the codes were organised into categories. Appendices D-F show all the codes and categories corresponding to the content analysis process of each year. Table 1 presents the categories identified each year including 11 categories identified in the first year, and 8 categories in the second and third year. Finally, 12 insights were identified, including brokenness, repair-worthy objects, value, etc.

Table 1. Twelve insights were identified related to product repair, design, and sustainability.

\begin{tabular}{ccc}
\hline 1st Year Insight Categories & 2nd Year Insight Categories & 3rd Year Insight Categories \\
\hline Repair Activism & Repair Activism & Repair Activism \\
Repair-Worthy Objects & Repair-Worthy Objects & Repair-Worthy Objects \\
Value & Value & Value \\
Aesthetics of Repair & Aesthetics of Repair & Aesthetics of Repair \\
Attachment after Repair & Attachment after Repair & Attachment after Repair \\
Reproducibility of Repair & Reproducibility of Repair & \\
Social Aspect & Social Aspect & Nature of Repair \\
Nature of Repair & & Designed Repair \\
Designed Repair & & \\
Perspectives of Repair & & Repair Motivation \\
Brokenness & Repair Motivation &
\end{tabular}




\section{Repair Insights}

\subsection{Repair-Worthy Objects}

This insight was about the concept of worth attributed to an object considered for repair. Some students questioned and negotiated whether the objects that they chose were worth repairing or not. By this we mean the ways that repair was negotiated regarding function, value, and the meaning of the product. What was deemed worth repairing was usually tied to the repair's economic costs, required time and effort, the environmental impacts of the repair, the perceived value of the object, and its meaning for its owner. For example, student 29 did not consider the coffee grinder worth repairing because the material was in a bad condition; it was made from wood and some parts of the wood had rotted. Some students also discussed that, in some cases, it might be more environmentally friendly to buy a new product than repairing it, for example, when the repair process requires using more materials than producing a new product.

\subsection{Value}

This insight is related to the value that repair creates and how the repair process makes people understand an object's value. Recreating, keeping, and adding value through repair are relevant explorations in terms of the aim of the assignment. The current linear perspective imposes the idea upon users that an object's value gradually diminishes after purchase [24]. However, this insight is about valuation as a continuous process evolving throughout the object's lifespan. For example, some students explained how the repair process, and the time and work they spent on the project, enabled them to realise and appreciate the value of the time and work that went into designing and manufacturing products.

The relationship between the value of the products and how this affected students' decisions to repair them was another discussion topic related to the value insight. For example, Student 16 explained her repair decision process in detail: "I discovered that I valued my products in different ways, that they were important from different aspects. I divided the values into three categories: monetary, emotional, and functional. The combined value in combination with my ability to repair as well as triggers for repairing determined whether or not my stuff got repaired". With these examples, we see that students gained some insights related to the value of products and different valuation types.

\subsection{Repair Motivation}

Understanding motivations and barriers is important in terms of understanding repair behaviour and designing for repair [25]. Some students had never tried fixing something before and had negative preconceptions. After repairing a product, most of those students said that their motivation increased. For example, student 42 declared that "After trying repair, I am far more motivated to repair broken objects that I own." Furthermore, students discussed the factors that affected their motivation to repair that they identified during their repair processes and through a review of the literature. The products' perceived values, the ability to repair, and emotional attachment were some of the motivation factors that students discussed during the focus groups. They also discussed the barriers that they experienced before the repair process which might have caused their negative preconceptions. The lack of knowledge about how to repair products, striving for perfection and aesthetic concerns were the barriers that they mentioned.

\subsection{Attachment after Repair}

Repairing objects sometimes created new emotional bonds or deepened the existing bonds between people and products. Some students declared that during the repair process, they recognized their emotional bond with the broken and neglected items. Similarly, others claimed that they reconnected with the memory of the object. Through repair, they also learned more about the product: its structure, material, mechanism, value, and cost, etc., so that they built a closer connection to the object [25]. Student 8's paper lantern repair was an example of how product attachment occurred, and new meanings could be embedded 
into products through repair. Student 8 repaired the torn lantern with her daughters. This resulted in a bonding time between the family members and affected the emotional value of the product. During a studio critique session, she declared that: "This could be the cheapest and a valueless object for anyone else, but it is one of the most valuable objects in my house after the repair."

\subsection{Designed Repair}

How do you determine how to repair something? How do you design a repair? What are the similarities and differences between the repair process and the design process? These were some of the questions that came up during the discussion about design and repair. Repair is frequently associated with mundanity, making do and lack of resources, whereas design is associated with innovation, technology, and trends. However, the repairer needs to make new design decisions during the repair process. As he/she works on an already designed product with damaged parts, technical and aesthetic features of the product are considered while making these design decisions. Most of the repair projects enabled students to experiment with the process through designing. In the 3D comb (Student 5), saucepan handle (Student 16) and pot handle (Student 25) projects, students designed various repair solutions.

\subsection{Aesthetics of Repair}

Visible repair stands out and differs from the overall look of the product in terms of aesthetics as it is made from a different material, or it is in a different colour. It creates a different aesthetic language, compared to the shiny and fragile surfaces of some of the currently available products. Rather than trying to hide the damage this language focuses on creativity and encourages the thoughtful assessment of the damage and repair. Student 17 emphasized the difference between the aesthetic language of the new products and the personality and the character of the old and repaired ones as: "After this project, I've started to think about repair in a different way, that it doesn't have to be perfect or professionally done. With simple means, my ragged armchair got a new personality." Similar examples and discussions during the focus group sessions showed that students gained some insights related to the aesthetic aspects of repaired products.

\subsection{Nature of Repair}

This insight questions what can be called repair. How far can we go with the repair in terms of changing the object's look or altering the way it is used? What is the difference between repair and upcycling? Repair refers to the act of bringing a damaged or faulty object back to a usable condition. This damage can be related to functional or aesthetic defects. The aim is to eliminate the problems that disturb or intervene with the usual ways a product is used. Upcycling, on the other hand, can be applied both on the material level or the object level. For the object level, it is the process of transforming discarded, faulty, or out of order objects into something of higher value in their second life [26].

Considering these definitions, some projects completed in this course can be considered as upcycling projects rather than repairs. For example, Student 1's object was an operating clockwork as can be seen in Figure 1. The clockwork was functional, but it was missing the clock face and the handset. Instead of only creating a new clock face and the handset, the student created a whole new product and changed the way it works. In her new design, the clock face turned to show the time without the handset. The clock face completed one turn in $12 \mathrm{~h}$ and the dots between the numbers represented each quarter of the hour. Similarly, Student 14 reconstructed a broken glass lampshade and created a new product (Figure 2). He used the broken glass pieces after sanding the edges. He designed and 3D-printed a body part and joints. Then, he used joints and red wires to attach glass pieces to the body. As seen in these examples, some products were reconstructed and redesigned although the function of the objects were kept the same after each intervention. 
These types of projects fuelled the discussion around the nature of repair and the line between repair and upcycling.

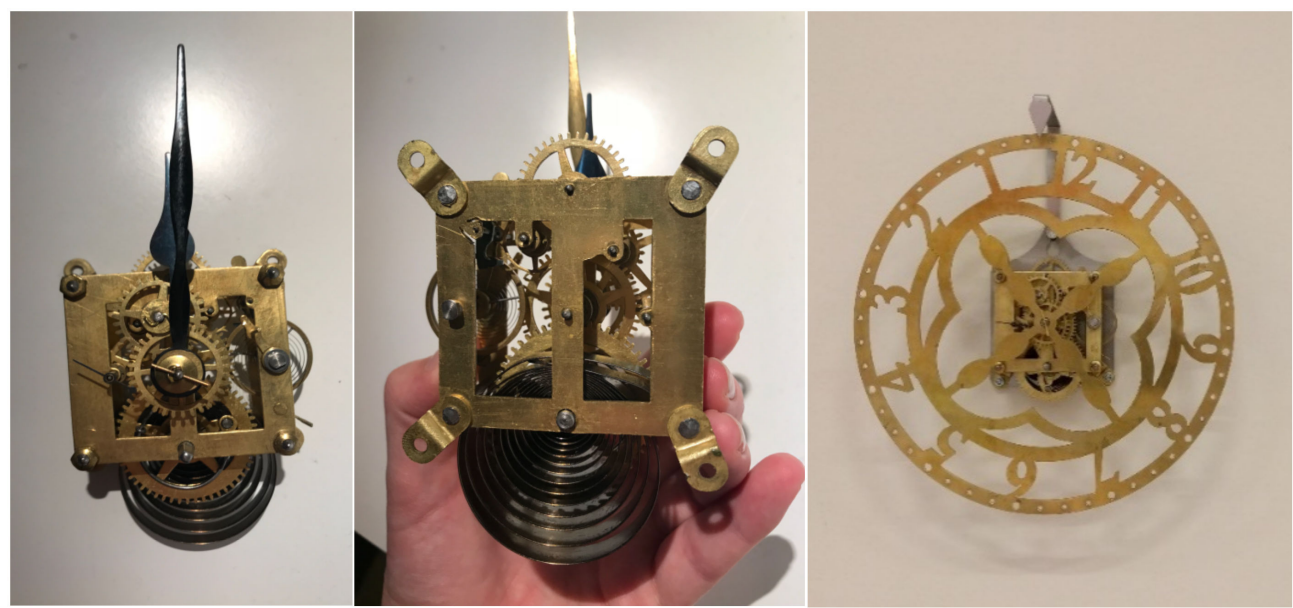

Figure 1. Two photos on the left show the clockwork mechanism without a clockface before the repair and the photo on the right is the clockwork mechanism after it was repaired by Student 1.

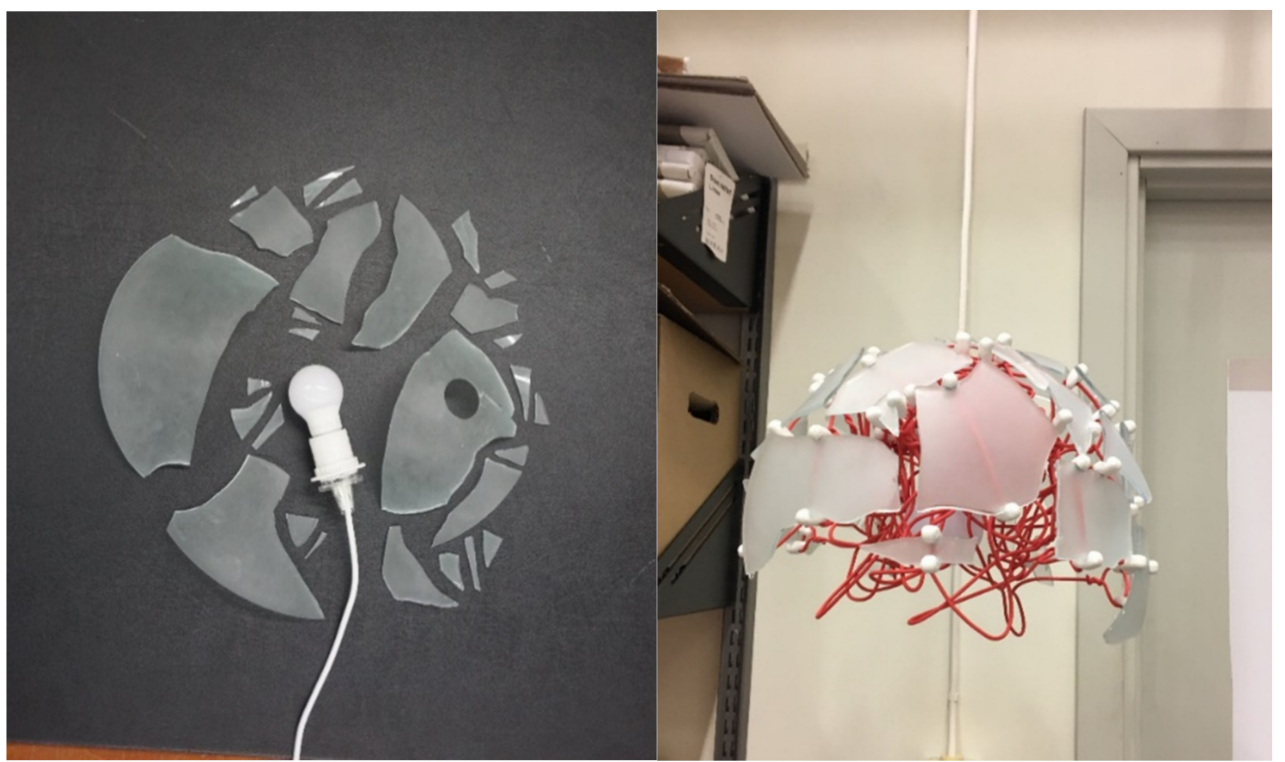

Figure 2. Student 14 reconstructed the broken glass lampshade and created a new one by using the broken glass pieces and 3D-printed parts.

\subsection{Brokenness}

What makes a product broken? Are there different kinds of product failures? What happens if the product is incomplete or missing a part, or has lost its value and needs a new aesthetic update? These were some of the questions that came up during the discussion related to this insight. If the product is functioning well but has some ripped parts, can we call it broken? Even if a malfunction does not interfere with a product's function or performance the user might still regard it as broken. Students had the freedom to decide "what broken is" and "what repair is" themselves, so this provided a range of products which were broken in different ways. Out of the 52 products that students repaired we saw different kinds of brokenness, including products with physical damage, incomplete products, and products with functional and aesthetic issues.

Student 1's clockwork repair was briefly explained in Section 3.7. It did not have any damaged parts, but it was not working because of the missing part. Student 10 worked 
with cutlery with aesthetic issues since the cutlery did not have any physical damage or functional issues. However, the owners did not want to use the cutlery because of aesthetic reasons as they were not matching.

\subsection{Reproducibility of Repair}

This insight emphasizes repair as a repetitive activity in an object's life because failure can emerge spontaneously and several times during an object's life. Similar damages can also reoccur as it is not always possible to prevent the factors that damage the product. In that case, repair methods and materials that are easily accessible and applicable can be chosen to increase the possibility of multiple repairs. For example, Student 6 used yarn, an easily accessible material, to repair the broken doll stroller which already had signs of previous repairs. The aim was to show the owner of the product that it was possible to repair it easily. Similarly, Student 17 decided to repair her armchair, of which her two cats had been scratching the fabric repeatedly. The repair process of this armchair will continue as the cats continue to scratch the fabric. Accordingly, she adopted a repair perspective that enables the product to evolve as it gets damaged and repaired. She chose to embroider the ripped parts with colourful thread, as the material was available, accessible and the method could be repeated many times.

When one repairs a product, the result has an impact on the possibility of future damage and the repair of the product. The repair might make the product prone to damage or might make it stronger. Similarly, the completed repair might make it easier or harder to repair the product afterwards. For example, Student 5 's plastic comb repair enabled the product to be repaired repeatedly. This plastic comb had some of the teeth broken and missing. She designed a tooth and a body that a couple of teeth could be inserted through. This body makes the teeth stable then it is attached to the broken comb through its remaining teeth. The teeth are modular so when one of them breaks, the user can dismantle and change it. This feature enabled the product to be repaired in the future if a similar problem happens again.

\subsection{Social Aspects}

Repair usually enables social interaction whether you find a repairman, ask someone who has the skills to fix your object, or you attend a repair café. In this project, the collaborative aspect of repair led to two types of gains: learning from collaboration and bonding through repair. In the former, students collaborated with the technicians in the workshop and requested an expert opinion outside the university and learned from these collaborations. In the latter, students asked each other or their families for help and ideas. For example, Student 8's paper lampshade repair was valuable in terms of emphasising the bonding through repair. It was a great example of bringing people together as she included her children in the repair process.

\subsection{Repair Activism}

Repairing products that are manufactured in way that makes repair difficult, and making repair visible are ways of activism in an age of overconsumption. Students discussed that a repaired object carries a message about our attitude towards caring for our planet, especially a visibly repaired one. Visible repair attracts people's attention, and this has the advantage of spreading the message, because by attracting people's attention, a conversation might start which might create awareness. The disadvantage, on the other hand, is related to the negative stigma attached to repair. Some people do not want to use visibly repaired objects because they are ashamed of repair in their value system, which is related to poverty and lack of resources, etc. This point was discussed in Student 3's project critique sessions. She mended some leggings that had the same damage inside of the thighs. She used bright-coloured thread and sashiko techniques, which are a traditional Japanese decorative embroidery. The discussion was about wearing these leggings and whether she would wear them or not. She said that she wanted to wear 
them, but she had some concerns and hesitation. Although, repair activism had other dimensions that students did not mention, such as the right-to-repair movement and repair organisations, the discussions showed that the students gained some insights on repair activism, especially with relation to the symbolic values that objects could carry.

\subsection{Perspectives of Repair}

Artistic, industrial, or critical were some of the different perspectives that students used in their projects. Some of them decided which perspective to use at the beginning while others decided during the process, depending on the nature of the damage, design of the product, and the repair methods. For example, Student 2 repaired his bicycle with an industrial perspective then he added an artistic aspect by painting it in a contrasting colour. The hinge of the folding bike was broken and became thin and weak due to rusting. With the help of the staff in the university's workshop, he created a new hinge by welding nuts to the remaining part of the hinge and machined a metal axle to go through these nuts (Figure 3). He drilled through the nuts to remove the threads before welding them to the bicycle. Finally, he painted the newly created hinge to prevent it from rusting again. By purposely selecting a contrasting colour, he wanted to highlight the repair. In this example, the functional repair and the aesthetic repair perspectives were used together.

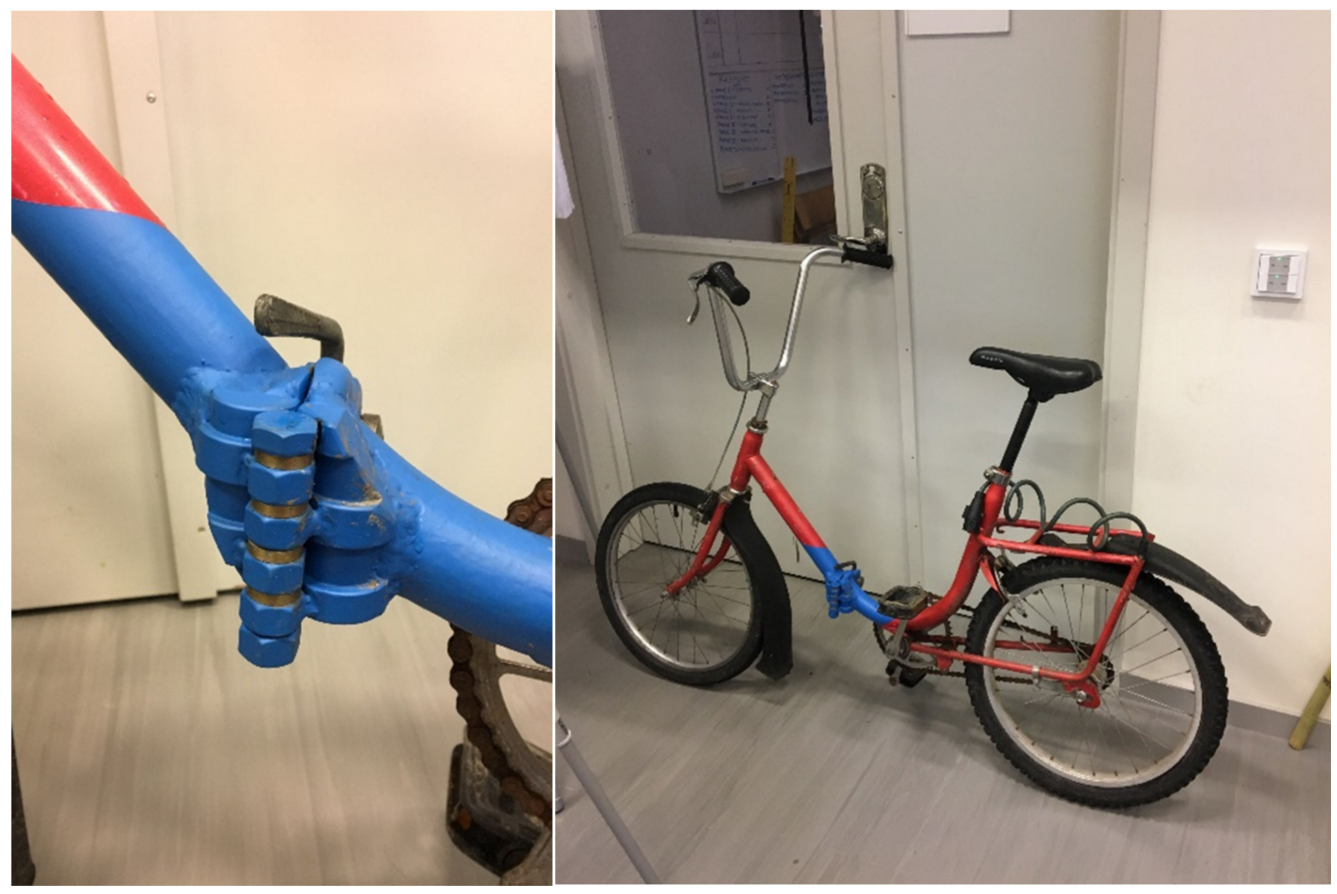

Figure 3. Student 2 repaired the hinge of his bicycle with an industrial perspective, and then painted the repaired part to prevent it from rusting.

Student 4 adopted an artistic perspective from the beginning of the project. He repaired broken ceramic cups by covering them with concrete and shaping them with cylindrical moulds (Figure 4). Then, to highlight the broken parts he used kintsugi; a traditional Japanese repair method of mending ceramic products with gold and silver powder. He explained why he used these two different materials with the contrasting meanings with these words: "I liked the idea of using cement, a strong a sturdy material, to contrast the fragility of ceramics and create something that identified with longevity rather than fragility." Having various repair projects showed the possibilities of combining different repair perspectives in practice and supported the discussion about this insight during focus group sessions. 


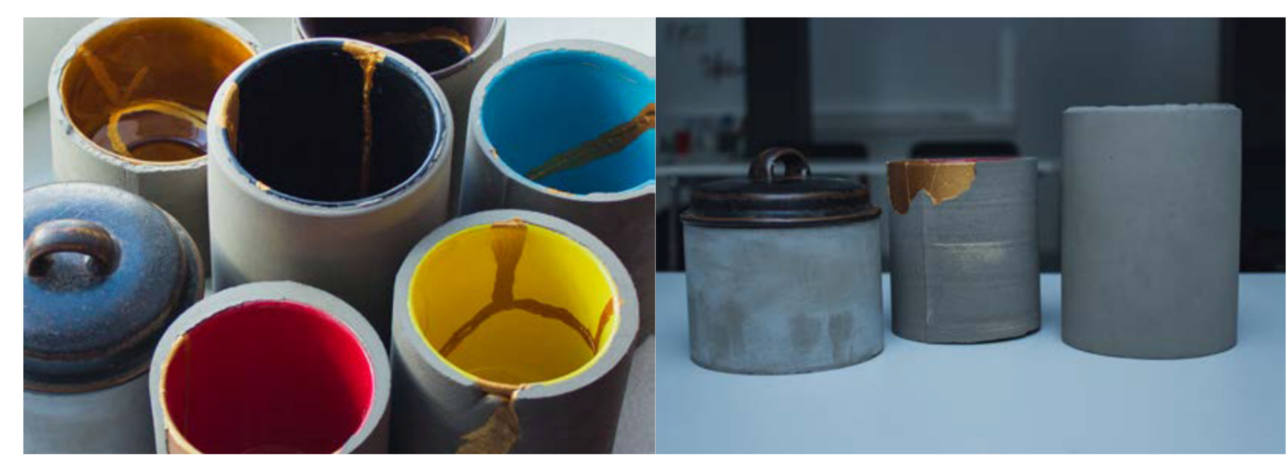

Figure 4. Student 4 adopted an artistic perspective from the beginning of the project. He repaired broken ceramic cups by covering them with concrete and shaping them with cylindrical moulds.

\section{Discussion}

Findings show that the practices of repair constitute complex sites of learning, technical skill and knowledge which can enable novice designers to gain competencies related to repair and circular design. The skillsets needed for the changing role of the designer in a circular economy were explored by some researchers [16-18]. However, those studies explored the subject area from a wider perspective than in our research; we particularly focused on repair while those studies considered the general sustainability competencies. In this paper, we recognized some competencies that are needed for designing repairable products such as reproducibility of repair, repair-worthy objects and designed repair categories. Firstly, the reproducibility of repair could be considered as a design for multipleuse cycles competency that Sumter et al. [17] identified. While both consider possible future problems related to long-term use or other factors during the design process, the former focuses specifically on repair. Secondly, we observed that the knowledge of how to decide what is worth repairing or not is needed to successfully design repairable products or to design a repair. In Section 3.1, we mentioned some aspects that could affect what is worth repairing, such as a repair's economic cost, required time and effort, etc. This category can be also considered as a part of other competencies that were identified in the literature before (e.g., design for recovery [17] and understanding failure modes and maintenance procedures) [16], but, again, those studies did not mention how to decide what is worth repairing. Accordingly, this discussion shows that further research is needed to identify the skills needed to design for the inner loops such as repair, reuse, and remanufacturing.

Some new future design competencies that are required to design repairable products are discovered during this research. Initially, the skill of solving aesthetic and structural problems of broken products is needed as the design possibilities are limited with already the existing products. Material knowledge is also required as the accessibility of materials and methods is one of the main barriers to product repair (25). Additionally, material knowledge is crucial for choosing long-lasting and gracefully ageing materials for product longevity. Designers should also be able to visualise the possible breakdown scenarios and identify the frequently used parts and the parts that could get damaged easily. Lastly, we observed that carrying out reverse engineering was helpful to understand the design of the damaged object and to design a suitable repair solution. This could be done through disassembling and analysing the materials and understanding how the product was used through observing the traces.

Although the focus of this assignment was on repair, the identified insights could inspire and help educators integrate other approaches to designing sustainable products, such as designs for upcycling, maintenance, and reuse. Insights into the aesthetics of repair, value, and repair-worthy objects could be discussed, with regard to other approaches. For example, the aesthetics of repaired, reused, and upcycled products differed from the aesthetic language of the ones produced in the current linear system. The adoption of these approaches could create a new aesthetic language that is more suitable for sustainable products. This argument is also true for the value insight. The adoption of these approaches 
requires a new value system that would not diminish the object's value after purchase. Lastly, the question of what is worth repairing, regarding the repair-worthy objects insight, is also valid for upcycling and reuse. We observed that students needed support in determining what is worth repairing. Similarly, they may need support in deciding what to upcycle and reuse, in order to choose the most beneficial option for the environment.

The study of repair as a design practice has the potential to extend the product lifespan and close the material loops. Considering these insights during the design process could enable more sustainable design solutions and result in products that are easier to repair, upcycle and remanufacture. However, more fundamental changes in the existing design practice towards fully embracing sustainability are urgently required. The approach we adopted in this study was the opposite of the existing design practice that focused on creating waste by selling more products. Design must stop serving the linear consumerist system and change its direction towards projects that are beneficial for the environment and society. Higher education institutions play a crucial role in this change and a new education system based on sustainability principles must be developed.

This assignment is valuable not only for designing repairs for existing products but also for designing for repair when conceiving a new product. Designing for repair necessitates allowing the products to be disassembled, providing the repair knowledge and the spare parts. It also means embracing the spontaneity and complexity of breakdown. There are a variety of ways that a product can become damaged. Apart from the frequently used parts, any product part can get damaged anytime. In this assignment, students experienced these notions about design for repair. They experienced the spontaneity of breakdown first-hand when the damaged products that they were working on broke again. They worked on products that were broken in various ways. They disassembled products and identified the problems with the disassembly. They also searched for spare parts and, most of the time, designed and created their own product parts.

Repair has both advantages and disadvantages for incorporating it in the product design curriculum. Students learn that planning a repair has similarities to a design process, specifically for unique designs, such as craft objects. It also helps them reflect on the inherent notion in product design discipline that the solution is always a newly designed product. For teachers, the examples and perspectives can already serve as a basis for incorporating repair in a lecture format and inspiring adaptation in hands-on assignments. Additionally, it provides a hook for questioning the fundamentals of product design as a field. Another advantage of integrating repair into product design education is that it is a hands-on activity and an effective way to encourage students to work practically and create prototypes. However, it is important that instructors place emphasis on all stages of the repair process. Students need guidance on the three phases of a designed repair process: discovery, idea generation and implementation [27]. For example, Students 11 and 12 spent most of their time on the implementation phase and neglected the first two phases. Their final repair solutions would have been more creative and aesthetically pleasing if they had put more effort into the idea generation stage, especially via sketching and visual representation.

As a result of this research, we want to present a more detailed version of the repair design process that Terzioğlu [27] explained in her paper. The repair design process includes discovery, idea generation, and implementation stages, and we identified the research stage as an addition to these three phases. The diagram in Figure 5 illustrates the different stages and the flow of the process between these stages. Discovery is the first phase of the repair design process, which includes two steps: inspection and determining the worth. At the inspection stage, the repairer inspects the problems and observes the features of the broken products through inspecting the damage, disassembling the product, analyzing its materials, and diagnosing the problem. Understanding how the product was used is also a significant step as it could help prevent the same damage from happening repeatedly. Traces on the object could be followed, such as the parts and surfaces that are worn down, to better understand the cause of the damage. The results of the discovery 
stage feed the decisions during the idea generation process. Idea generation involves creative thinking because, at this stage, the repairer starts to think about repair solutions for the damaged product. The repairer develops design ideas following the steps of making aesthetic and structural decisions, and considering the reproducibility of repair. To find successful solutions, the repairer can consider and research alternative methods and materials for the repair. The idea generation stage and the research stage are usually intertwined but they could be processed separately depending on the specific requirements of the repair process. Which materials, methods, and tools are needed to implement the repair are researched at the research stage. Amateur repairers can search for online repair videos or contact experts for more information. Lastly, the decisions made, and the solutions developed during the idea generation stage, are implemented at the implementation stage. Prototyping is an effective way to explore and observe whether the solutions work for the particular damage that the repairer is dealing with or not. This stage usually proceeds iteratively with the previous stages. If the identified repair solution fails, the repairer could go back to the discovery or idea generation stage to develop a better solution. The activities of the assignment were designed in a way to fit into this repair design process. Students were informed and directed about the different stages of the process during the studio discussions.

\section{REPAIR DESIGN PROCESS}

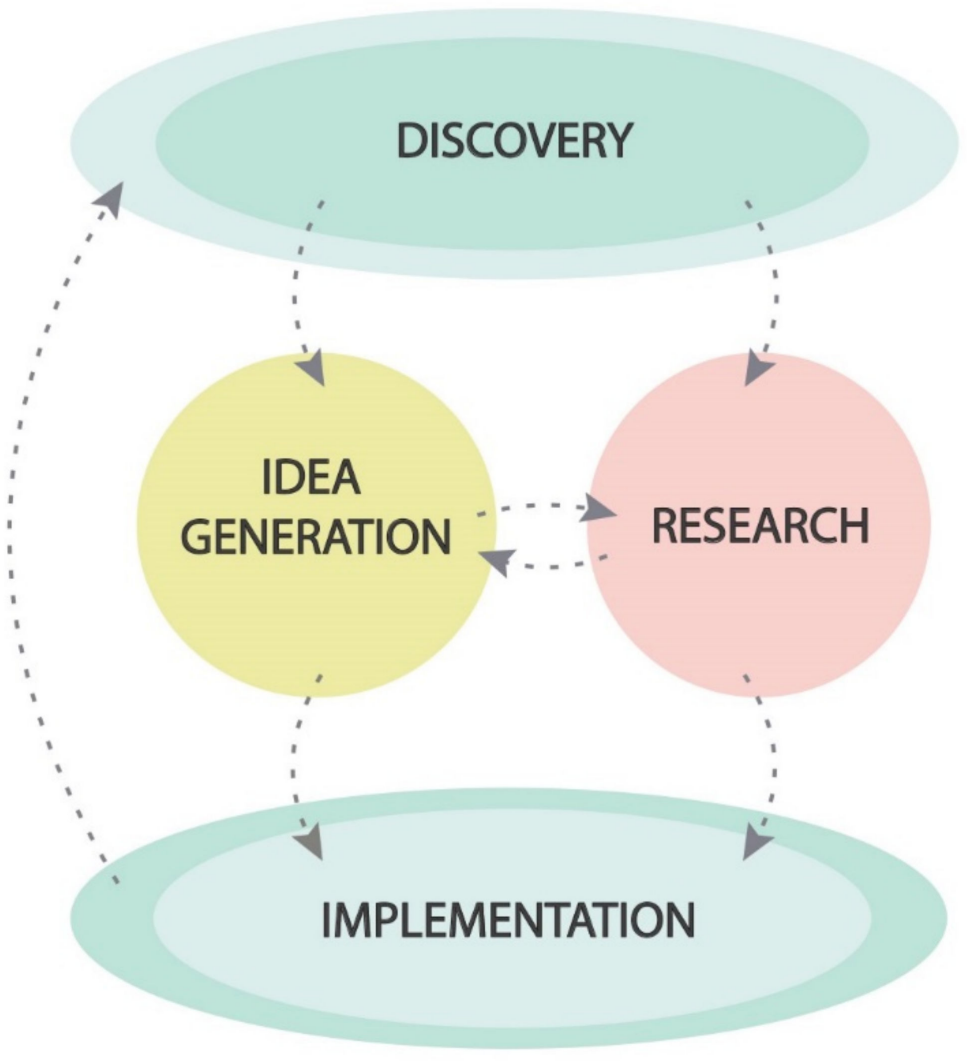

Figure 5. The repair design process includes discovery, idea generation, research, and implementation stages.

In this assignment students dealt with the real problems of repair, instead of imagining the breakdown reasons and possible problems that could occur with a newly designed product. In the case of the saucepan handle, Student 16 solved a couple of problems in a real-world context. For example, she needed to find the metal connection piece that connects the handle to the lid. Then, she designed a new longer-lasting handle to replace the broken one. As the connection piece was not available online or in any hardware store, she 
needed to contact the producer. This process showed the difficulties with repairing objects in the real world. Designing a new object was a design-focused activity whereas designing repair was a repair-focused activity where design was used as a means to reach the aim. When we reviewed the insights, we realised that dealing with product breakage provided different knowledge to students, compared to designing a new object and anticipating possible breakdown reasons.

Each year, analysis of the collected data resulted in different insights, but as it can be seen in Table 1, the third year's research did not yield any new findings. The point of reaching data saturation is achieved when further data adds no new information to the research aim, and when there is enough information to replicate the study [28]. Data saturation was achieved in this research when the data became repetitive and did not necessarily add anything new to the aim of the research. In the third year, no additional data were found to develop new categories, so this research was concluded.

\section{Conclusions}

This paper sheds light on the complexity of repair as a subject area and, through certain insights, we understood repair's dimensions further. This research is valuable for design practice as it provides concrete examples and insights from repair processes. It is valuable for academics as it shows an example of incorporating repair into design education. The insights developed in this research can be explored further, whereas some of them can be taken into consideration in future research regarding product repair.

Repair ought to be part of design education, at the very least for those design curricula that cover product design. Educators in those programs might choose to implement this exact same assignment. Based on our experiences we would propose the following pointers:

- The focus group sessions, in which you generate the themes overarching the individual repairs, are as important as the long process in which the students generate their repairs. They contribute a large part to students' knowledge if the objective is to truly reflect on the relationship between design, repair, and sustainability;

- To generate such overarching insights, students should be given maximum freedom in choosing objects and repair techniques, as well as in defining what is broken and what constitutes repair;

- Combining this assignment with other repair-related assignments, such as hosting a repair café, further strengthens learning;

- If a full repair exercise is beyond what is feasible for a program, the examples of repair in this paper, combined with the perspectives generated, should still be an effective basis for a shorter lecture or workshop exploring the notion of design and repair.

Author Contributions: Conceptualization, N.T. and R.W.; methodology, N.T. and R.W.; formal analysis, N.T.; investigation, N.T. and R.W.; resources, N.T. and R.W.; data curation, N.T.; writing-original draft preparation, N.T.; writing-review and editing, N.T. and R.W.; visualization, N.T.; supervision, N.T. and R.W. All authors have read and agreed to the published version of the manuscript.

Funding: This research received no external funding.

Institutional Review Board Statement: Not applicable.

Informed Consent Statement: Not applicable.

Acknowledgments: We would like to thank all our students who participated in this course.

Conflicts of Interest: The authors declare no conflict of interest. 


\section{Appendix A}

LiU MSc Design

TMKA08 Studio 1

Fall 2020 semester

\section{DESIGN, SUSTAINABILITY \& REPAIR}

dr. Renee Wever

dr. Nazlı Terzioglu-Özkan

\section{Introduction}

In TMKA08 Studio1, we will explore how design and sustainability relate to actual repair of products. Repair has been selected as a topic, because the questions involved in making repair actually happen, cover many different types of design: (technical) product design, service design, information design. Furthermore, many different aspects, such as aesthetics, economics, engineering, and psychology are relevant.

Hence, it is a well-suited topic for students from different educational (and cultural) backgrounds, as well as being suited for students in the three different tracks that the MSc Design program offers.

\section{Multiple perspectives}

The make our exploration as meaningful as possible, we will not do one single assignment, but multiple smaller projects, each exploring different aspects of design, sustainability and repair. There will be three sub-projects exploring three angles, and in the end some form of reflective external communication.

Within each of the three initial sub-projects, we will:

- have one or more hands-on workshops,

- read and discuss relevant academic literature,

- have a seminar with a relevant researcher,

- do a design or design research assignment.

\section{Beautiful repair:}

This perspective will be covered during the first half of the semester. Make one (or more) beautiful, visible repairs. (individual)

Find a (set of) broken/damaged product(s) and explore their repair.

Strive for visible, yet aesthetically pleasing repair. Resulting products will be unique.

This is about (craft) skills. Obviously, you all have different pre-existing skill sets. That is fine.

Assignment (individual):

Find an object that is broken, and make a visible, beautiful repair

Coaching meetings: Wednesdays $9-16$

Deadline: oct $28^{\text {th }}$

Lecture: Naz|ı Terzioglu-Özkan "Beautiful repair, different visible repair examples and methods" Wednesday, September $2^{\text {nd }}, 9: 15-10: 00$

Hands-on Kintsugi workshop (by Nazlı Terzioglu-Özkan)

Schedule:

Norrköping September $9^{\text {th }}, 9: 15-12: 00$

Linköping (2x) September $23^{\text {rd }}, 9: 15-12: 00$

Hands-on workshop: intro to metal and wood workshop [remember to social distance!]

Schedule:

Norrköping (and late arrivals) September $23^{\text {rd }}, 10: 00-12: 00$

Linköping (2x) September 9th, 9:00-11:00

Papers:

- McLaren, A., \& McLauchlan, S. (2015). Crafting sustainable repairs: Practice-based approaches to extending the life of clothes. In T. Cooper, N. Braithwaite, M. Moreno, \& G. Salvia (Eds.)

Proceedings of the Product Lifetimes and the Environment Conference (pp. 221-228). Retrieved from http://www. plateconference.org/conference-2015/

- Ozkan, N. (2019). Investigating user perspectives related to product repair towards a circular economy. PLATE 2019 Conference, 18-20 September 2019, Berlin, Germany.

Seminar to discuss them

Wednesday September $16^{\text {th }}, 9: 15-10: 00$

Figure A1. Brief of the Beautiful Repair Assignment. 
Appendix B

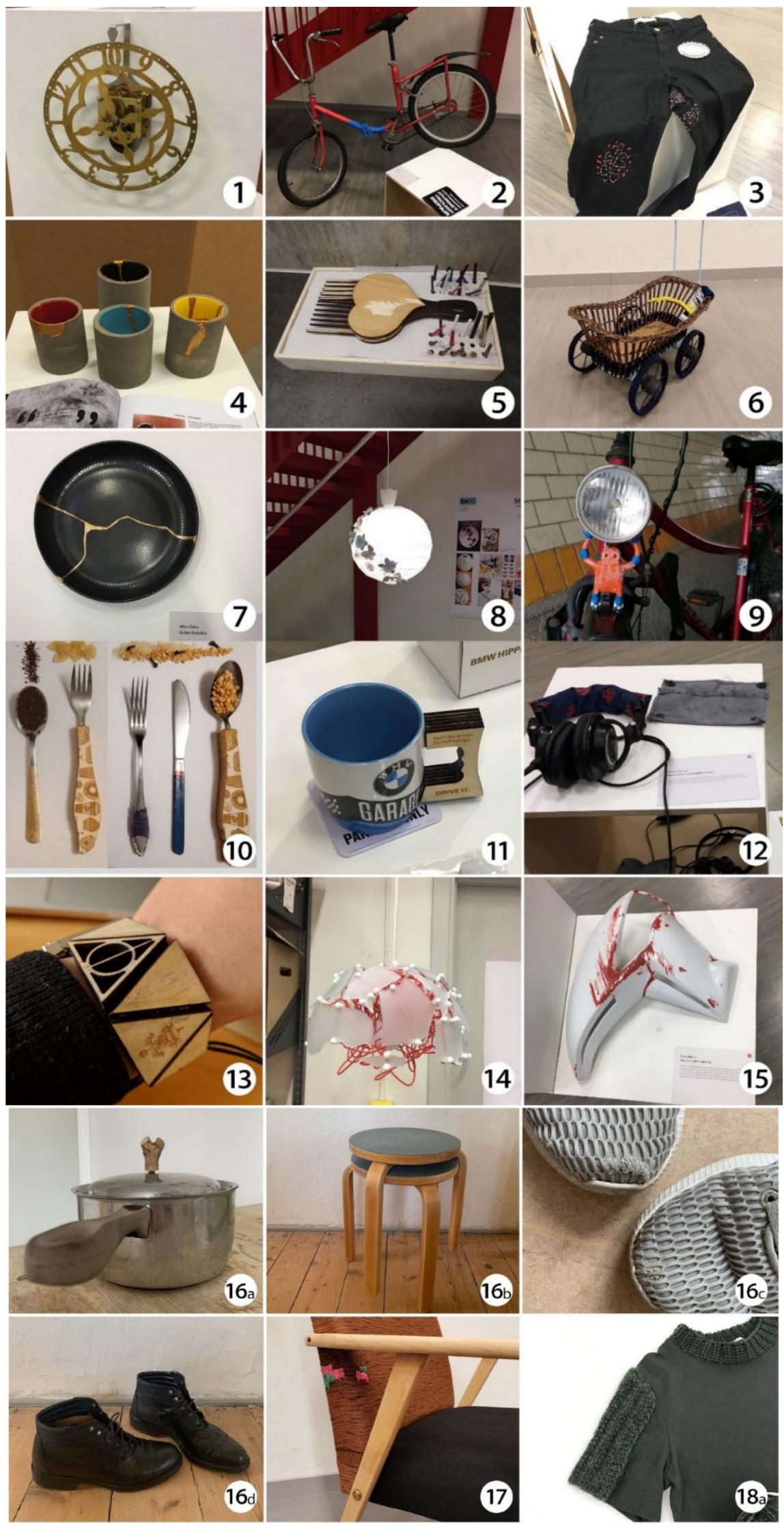

Figure A2. Cont. 


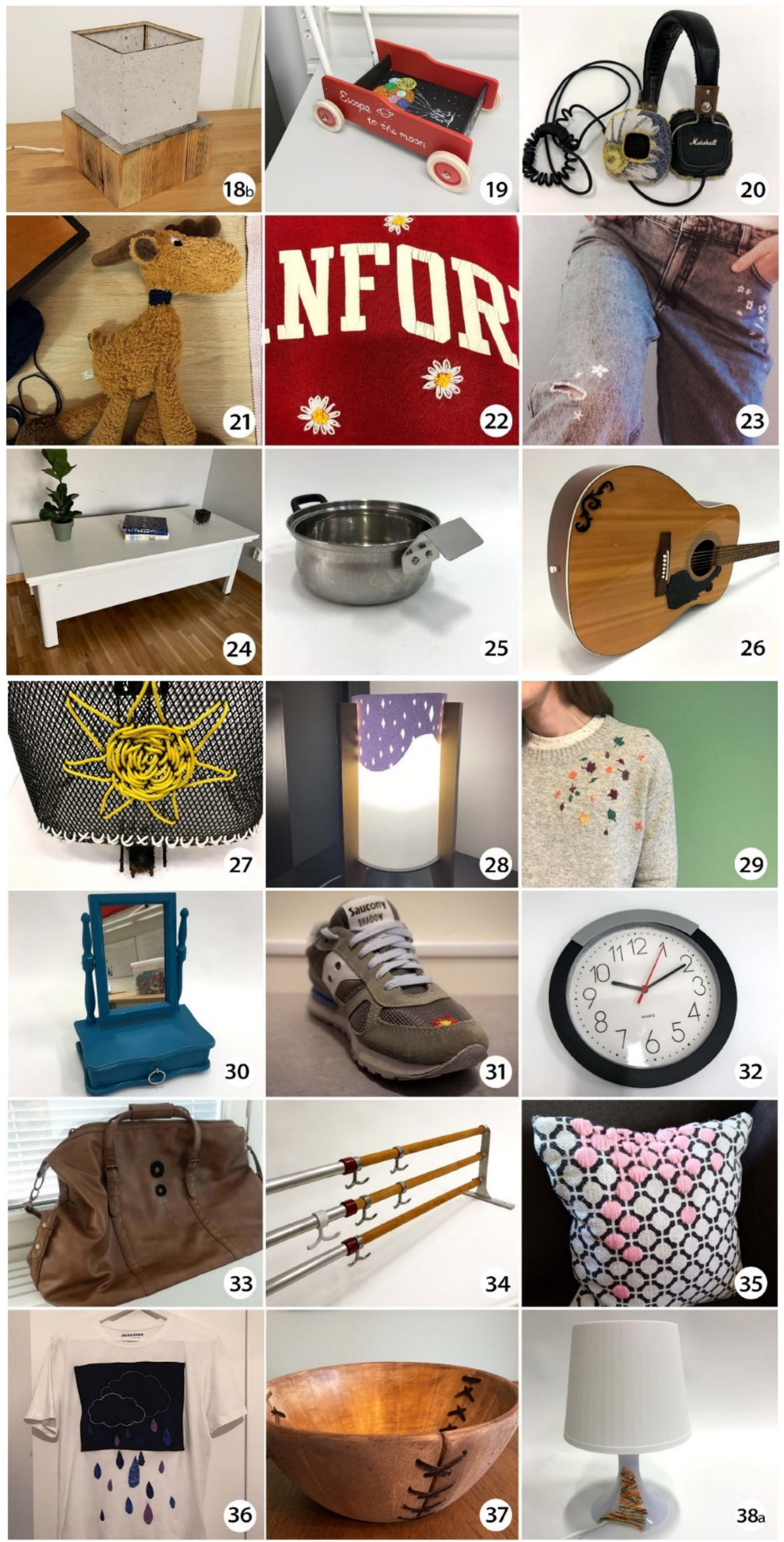

Figure A2. Cont. 

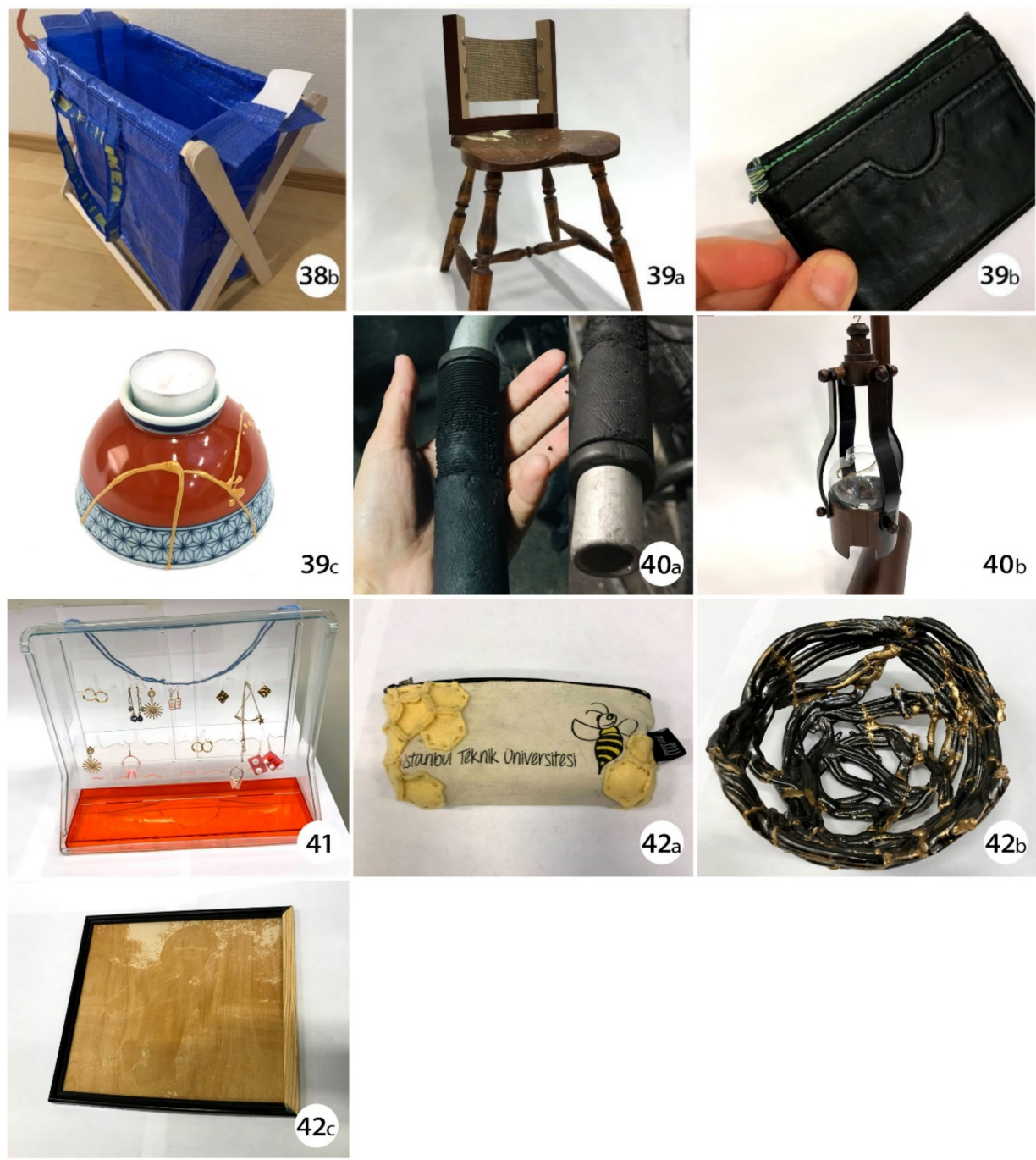

Figure A2. Photos of the Projects Completed as Part of the Assignment.

\section{Appendix C}

Table A1. List of Projects of the Students Who Participated in the Course.

\begin{tabular}{ll}
\hline Number & Project \\
\hline 1 st Year & \\
\hline 1 & clockwork mechanism \\
2 & red bicycle \\
3 & leggings \\
4 & ceramic concrete \\
5 & 3DP comb \\
6 & doll stroller \\
7 & kintsugi plates \\
8 & paper lampshade \\
9 & bicycle lamp \\
10 & cutlery \\
11 & BMW cup \\
12 & headphones \\
13 & watch strap \\
14 & glass lampshade \\
15 & motorcycle part \\
\hline
\end{tabular}


Table A1. Cont.

\begin{tabular}{ll}
\hline Number & Project \\
\hline 2 nd Year & \\
\hline 16 & (a) saucepan handle, (b) stool, (c) sneakers, (d) leather shoes \\
17 & armchair \\
18 & (a) t-shirt, (b) bedside lamp \\
19 & brio toddler wobbler \\
\hline 3 rd Year & \\
\hline 20 & headphones cushion \\
21 & dog toy \\
22 & sweatshirt \\
23 & jeans \\
24 & bathtub \\
25 & pot handle \\
26 & classic guitar \\
27 & bicycle basket \\
28 & glass lamp shade \\
29 & jumper \\
30 & tabletop mirror \\
31 & sneakers \\
32 & 3dp clock \\
33 & duffle bag \\
34 & train rack \\
35 & pillowcase \\
36 & t-shirt \\
37 & wooden bowl \\
38 & (a) bedside lamp, (b) Ikea bag \\
39 & (a) wooden chair, (b) card holder, (c) bowl \\
40 & (a) bicycle handlebar grips, (b) oil lamp \\
41 & freezer drawer \\
42 & (a) pencil case, (b) ceramic bowl, (c) picture frame \\
\hline & \\
& \\
\hline
\end{tabular}

\section{Appendix D}

Table A2. List of Codes Derived from the Content Analysis of the First Year's Focus Group Session.

\begin{tabular}{lll}
\hline Number & Code & Category \\
\hline 1 & what can be called repair? & nature of repair \\
2 & how far we can go with the repair? & \\
3 & altering the object's look & \\
4 & altering the function of the product & \\
5 & the difference between repair and upcycling & brokenness \\
6 & functional or aesthetic defects & \\
7 & what is broken? & \\
8 & in which ways is it broken? & \\
9 & what makes a product broken? & \\
10 & different kinds of brokenness & \\
11 & incomplete products & designed repair \\
12 & products a missing part & \\
13 & aesthetic problems & \\
15 & obsolete products & \\
16 & physical damage & \\
17 & functional issues & \\
18 & how to repair something in a beautiful way & \\
19 & the similarities between the repair and & \\
20 & the design processes & creativity in the design and repair process
\end{tabular}


Table A2. Cont.

\begin{tabular}{|c|c|c|}
\hline Number & Code & Category \\
\hline 21 & innovation potential of designed repair & \\
\hline 22 & artistic repair & perspectives of repair \\
\hline 23 & industrial perspective & \\
\hline 24 & critical perspective & \\
\hline 25 & kintsugi is an artistic repair & \\
\hline 26 & visible repair & \\
\hline 27 & mechanical repair techniques & \\
\hline 28 & electrical repairs & \\
\hline 29 & electronic repairs & \\
\hline 30 & repair creates value & value \\
\hline 31 & the repair process makes us understand an object's value & \\
\hline 32 & financial value of the objects after repair & \\
\hline 33 & emotional value of the objects after repair & \\
\hline 34 & aesthetic value of the objects after repair & \\
\hline 35 & recurring damage & reproducibility of repair \\
\hline 36 & need of multiple repairs & \\
\hline 37 & repair that can be repeated & \\
\hline 38 & preventive measures & \\
\hline 39 & the possibility of future damage & \\
\hline 40 & the possibility of future repair & \\
\hline 41 & making the product stronger through repair & \\
\hline 42 & making the product weaker through repair & \\
\hline 43 & making future repairs harder & \\
\hline 44 & making future repairs easier & \\
\hline 45 & visible repair & aesthetics of repair \\
\hline 46 & repairing with different material/in a different colour & \\
\hline 47 & dominant aesthetic understanding & \\
\hline 48 & gracefully aging & \\
\hline 49 & doesn't have to be perfect & \\
\hline 50 & learning from collaboration & $\begin{array}{l}\text { collaboration/ } \\
\text { social aspect }\end{array}$ \\
\hline 51 & bonding through repair & \\
\hline 52 & repair enables social interaction & \\
\hline 53 & storytelling & repair activism \\
\hline 54 & the negative stigma attached to repair & \\
\hline 55 & visible repair as a badge of honour & \\
\hline 56 & product replacement as the norm & \\
\hline 57 & the products that are worth repairing & repair-worthy objects \\
\hline 58 & what is worth repairing & \\
\hline 59 & are cheap products worth repairing & \\
\hline 60 & creating emotional value & attachment after repair \\
\hline 61 & bonding with the object & \\
\hline 62 & becomes the most valuable object after the repair & \\
\hline 63 & now has an emotional value & \\
\hline
\end{tabular}

\section{Appendix E}

Table A3. List of Codes Derived from the Content Analysis of the Second Year's Focus Group Session.

\begin{tabular}{lll}
\hline Number & Code & Category \\
\hline 1 & restoring functional value & value \\
2 & creating emotional value & \\
3 & product's value affects repair motivation & \\
4 & value is not fixed & \\
5 & financial value & \\
6 & emotional value & \\
\hline
\end{tabular}


Table A3. Cont.

\begin{tabular}{|c|c|c|}
\hline Number & Code & Category \\
\hline 7 & functional value & \\
\hline 8 & an understanding of the making of products & \\
\hline 9 & unpreventable factors that cause damage & reproducibility of repair \\
\hline 10 & multiple repairs & \\
\hline 11 & eliminating the factors that cause damage & \\
\hline 12 & enabling future repairs & \\
\hline 13 & repair as a continuous process & \\
\hline 14 & evolving products & \\
\hline 15 & evolving repairs & \\
\hline 16 & repair is inevitable & \\
\hline 17 & doesn't have to be perfect & aesthetics of repair \\
\hline 18 & different aesthetics & \\
\hline 19 & societal values & social aspect \\
\hline 20 & society rewards consuming & \\
\hline 21 & it is made difficult to choose repair & \\
\hline 22 & praise of new things & \\
\hline 23 & outspoken design & repair activism \\
\hline 24 & symbol of poverty & \\
\hline 25 & repair as an activist act & \\
\hline 26 & an object is worth repairing or not & repair-worthy objects \\
\hline 27 & a valuable product is more likely to be repaired & \\
\hline 28 & putting in the effort versus the repair result & \\
\hline 29 & emotional bond & attachment after repair \\
\hline 30 & emotional attachment & \\
\hline 31 & my ability to repair & repair motivation \\
\hline 32 & products value affects repair motivation & \\
\hline 33 & repair triggers & \\
\hline 34 & factors that motivate people to repair & \\
\hline 35 & product's value affects repair motivation & \\
\hline 36 & desire to make it look perfect & \\
\hline
\end{tabular}

\section{Appendix F}

Table A4. List of Codes Derived from the Content Analysis of the Third Year's Focus Group Session.

\begin{tabular}{lll}
\hline Number & Code & Category \\
\hline 1 & repair process is not predictable & nature of repair \\
2 & experimental & \\
3 & gaining experience & \\
4 & exploration & \\
5 & feeling puzzled & \\
6 & progressive & \\
7 & enjoyable & \\
8 & playful & \\
9 & emotional & \\
10 & relaxing & \\
11 & learning new skills & \\
12 & teaches patience & \\
13 & makes you find out your skills & \\
14 & creative ways of repairing & \\
15 & new ideas of how to repair & \\
16 & beautiful ways of repairing things & \\
17 & having a creative approach towards repair & \\
18 & to think of different ways on how to repair something & \\
19 & differences between a quick repair and designed repair & \\
20 & iterative trial and error process &
\end{tabular}


Table A4. Cont.

\begin{tabular}{|c|c|c|}
\hline Number & Code & Category \\
\hline 21 & creative thinking involved in designed repair & \\
\hline 22 & aesthetic creativity & \\
\hline 23 & nourish my creative side & \\
\hline 24 & create something that I find useful & \\
\hline 25 & create something beautiful & \\
\hline 26 & triggers you to think different & \\
\hline 27 & time and effort go into producing things & value \\
\hline 28 & awareness of the value of the objects & \\
\hline 29 & teaches you the value of a product & \\
\hline 30 & do not focus on perfection & aesthetics of repair \\
\hline 31 & the barriers related to perfection & \\
\hline 32 & striving for perfection is a barrier & \\
\hline 33 & handmade things are perfect in a different way & \\
\hline 34 & the message that repaired objects carry & repair activism \\
\hline 35 & visible repair shows the story of the product & \\
\hline 36 & $\begin{array}{l}\text { trying repair might motivate people to complete } \\
\text { more repairs }\end{array}$ & repair motivation \\
\hline 37 & trying repair changed my repair behaviour & \\
\hline 38 & $\begin{array}{l}\text { I am far more motivated to repair broken objects } \\
\text { that I own }\end{array}$ & \\
\hline 39 & change in my opinion about repairing something & \\
\hline 40 & my connection to repair changed & \\
\hline 41 & encourage people who are interested in repair & \\
\hline 42 & challenge and inspire people & \\
\hline 43 & sharing experience, to inspire & \\
\hline 44 & using accessible tools and materials & \\
\hline 45 & come up with a repair that can be applied by others & \\
\hline 46 & mental barriers experienced before the repair activity & \\
\hline 47 & $\begin{array}{l}\text { I did not have enough knowledge on how to } \\
\text { make the repair }\end{array}$ & \\
\hline 48 & the barriers related to perfection & \\
\hline 49 & the product's worth to be repaired & repair-worthy objects \\
\hline 50 & what is worth repairing & \\
\hline 51 & determining the worth of the object & \\
\hline 52 & it is meaningful to repair things with high value & \\
\hline 53 & creating sentimental value & attachment after repair \\
\hline 54 & emotional attachment & \\
\hline 55 & realizing emotional bonds in broken items & \\
\hline 56 & reconnecting with the memory of the object & \\
\hline 57 & reconnecting with the object & \\
\hline 58 & awareness of the value of the objects & \\
\hline 59 & realising the ignored object & \\
\hline 60 & revealing memories & \\
\hline 61 & built a closer connection to the object & \\
\hline 62 & care about the product more & \\
\hline 63 & $\begin{array}{l}\text { keeping and improving the sentimental value of the } \\
\text { objects through repair }\end{array}$ & \\
\hline 64 & better user-product relationship & \\
\hline 65 & learning the inner structure of products & \\
\hline 66 & understanding what constitutes an object & \\
\hline
\end{tabular}

\section{References}

1. Ellen MacArthur Foundation. Towards the Circular Economy Vol. 1: An Economic and Business Rationale for an Accelerated Transition; Ellen MacArthur Foundation: Cowes, UK, 2012; Volume 1.

2. Van den Berg, M.R.; Bakker, C.A. A product design framework for a circular economy. In Proceedings of the Product Lifetimes and the Environment Conference, Nottingham, UK, 17-19 June 2015; Cooper, T., Braithwaite, N., Moreno, M., Salvia, G., Eds.; Nottingham Trent University: Nottingham, UK, 2015. 
3. Bocken, N.M.; De Pauw, I.; Bakker, C.; Van der Grinten, B. Product design and business model strategies for a circular economy. J. Ind. Prod. Eng. 2016, 33, 308-320. [CrossRef]

4. Ghisellini, P.; Cialani, C.; Ulgiati, S. A review on circular economy: The expected transition to a balanced interplay of environmental and economic systems. J. Clean. Prod. 2016, 114, 11-32. [CrossRef]

5. Ramirez, M. Sustainability integration in industrial design education: A worldwide survey. In Proceedings of the Connected 2007 International Conference on Design Education, Sydney, Australia, 9-12 July 2007; The University of New South Wales: Sydney, Australia, 2007.

6. Andrews, D. The circular economy, design thinking and education for sustainability. Local Econ. 2015, 30, 305-315. [CrossRef]

7. Findeli, A. Rethinking design education for the 21st century: Theoretical, methodological, and ethical discussion. Des. Issues 2001, 17, 5-17. [CrossRef]

8. Norman, D. Why Design Education Must Change. 2010. Available online: https://www.researchgate.net/profile/Donald_ Norman/publication/235700801_Wir_brauchen_neue_Designer_Why_Design_Education_Must_Change/links/54a2b47e0cf2 56bf8bb0d448.pdf (accessed on 10 November 2018).

9. Scheer, A.; Noweski, C.; Meinel, C. Transforming constructivist learning into action: Design thinking in education. Des. Technol. Educ. 2012, 17, 8-19.

10. Meyer, M.W.; Norman, D. Changing Design Education for the 21st Century. She Ji J. Des. Econ. Innov. 2020, 6, 13-49. [CrossRef]

11. Wever, R.; Charnley, F.; Brass, C.; Harrison, L. Preparing designers for a circular economy goldrush; exploring the implications for education. In Proceedings of the Global Cleaner Production and Sustainable Consumption Conference, Barcelona, Spain, 1-4 November 2015.

12. Ramirez, M. Sustainability in the education of industrial designers: The case for Australia. Int. J. Sustain. High. Educ. 2006, 7, 189-202. [CrossRef]

13. Lofthouse, V. Social issues: Making them relevant and appropriate to undergraduate student designers. Des. Technol. Educ. Int. J. 2013, 18, 8-23.

14. Ellen MacArthur Foundation. Circular Economy and Curriculum Development in Higher Education. Available online: https:/ / www.ellenmacarthurfoundation.org/assets/downloads/higher-education/EMF_HE-Curriculum-Brochure-17 -JUNE_SINGLES.pdf (accessed on 10 January 2021).

15. Lilley, D.; Lofthouse, V. Sustainable design education-considering design for behavioural change. Eng. Educ. 2009, 4, 29-41. [CrossRef]

16. Papanek, V.J. Design for the Real World: Human Ecology and Social Change; Thames and Hudson: London, UK, 1971.

17. Edgerton, D. The Shock of the Old: Technology and Global History since 1900; Oxford University Press: Oxford, UK, 2007.

18. De los Rios, I.C.; Charnley, F.J. Skills and capabilities for a sustainable and circular economy: The changing role of design. J. Clean. Prod. 2017, 160, 109-122. [CrossRef]

19. Sumter, D.; De Koning, J.; Bakker, C.; Balkenende, R. Circular economy competencies for design. Sustainability 2020, $12,1561$. [CrossRef]

20. Wiek, A.; Withycombe, L.; Redman, C.L. Key competencies in sustainability: A reference framework for academic program development. Sustain. Sci. 2011, 6, 203-218. [CrossRef]

21. Stewart, D.W.; Shamdasani, P.N. Focus Groups: Theory and Practice; Sage Publications: Thousand Oaks, CA, USA, 2014 ; Volume 20.

22. Litosseliti, L. Using Focus Groups in Research; Continuum: London, UK, 2003.

23. Weber, R.P. Basic Content Analysis; SAGE Publications: Newbury Park, CA, USA, 1990.

24. Achterberg, E.; Hinfelaar, J.; Bocken, N. Master Circular Business with the Value Hill. 2016. Available online: https://www.circleeconomy.com/news/master-circular-business-with-the-value-hill (accessed on 1 August 2021).

25. Terzioglu, N. Repair motivation and barriers model: Investigating user perspectives related to product repair towards a circular economy. J. Clean. Prod. 2021, 289, 125644.

26. Sung, K. A review on upcycling: Current body of literature, knowledge gaps and a way forward. In Proceedings of the ICECESS 2015: 17th International Conference on Environmental, Cultural, Economic and Social Sustainability, Venice, Italy, 13-14 April 2015.

27. Terzioglu, N. Do-fix workshops: Understanding users' product repair experience. In Proceedings of the PLATE 2017 Conference, Delft, The Netherlands, 8-10 November 2017.

28. Fusch, P.I.; Ness, L.R. Are we there yet? Data saturation in qualitative research. Qual. Rep. 2015, 20, 1408. 